(

Check for

updates

Cite as

Nano-Micro Lett.

(2020) $12: 43$

Published online: 30 January 2020

(C) The Author(s) 2020

\section{Correction to: Ultrastable and High-Performance Silk Energy Harvesting Textiles}

\author{
Chao $\mathrm{Ye}^{1}$, Shaojun Dong ${ }^{1}$, Jing Ren $^{1}{ }^{凶}$, Shengjie Ling ${ }^{1 凶}$
}

The original article can be found online at https://doi.org/10.1007/s40820-019-0348-z.

$\bowtie$ Jing Ren, renjing@ shanghaitech.edu.cn; Shengjie Ling, lingshj@ shanghaitech.edu.cn

1 School of Physical Science and Technology, ShanghaiTech University, 393 Middle Huaxia Road, Shanghai 201210, People's Republic of China

\section{Correction to: Nano-Micro Lett. (2020) 12:12 https://doi.org/10.1007/s40820-019-0348-z}

In the original publication, there is line dislocation in Fig. 8d. The correct Fig. 8 is provided in this correction.

Open Access This article is licensed under a Creative Commons Attribution 4.0 International License, which permits use, sharing, adaptation, distribution and reproduction in any medium or format, as long as you give appropriate credit to the original author(s) and the source, provide a link to the Creative Commons licence, and indicate if changes were made. The images or other third party material in this article are included in the article's Creative Commons licence, unless indicated otherwise in a credit line to the material. If material is not included in the article's Creative Commons licence and your intended use is not permitted by statutory regulation or exceeds the permitted use, you will need to obtain permission directly from the copyright holder. To view a copy of this licence, visit http://creativecommons.org/licenses/by/4.0/. 
(a)



(b) $\mathrm{i}$
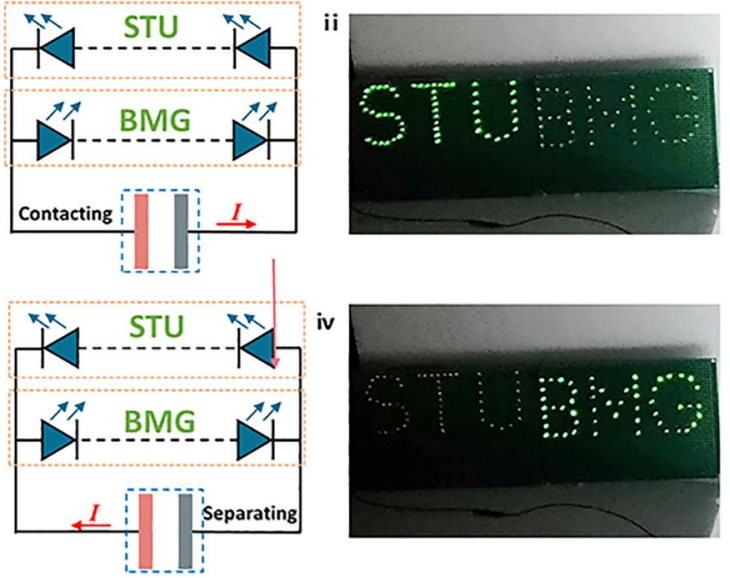

(c)

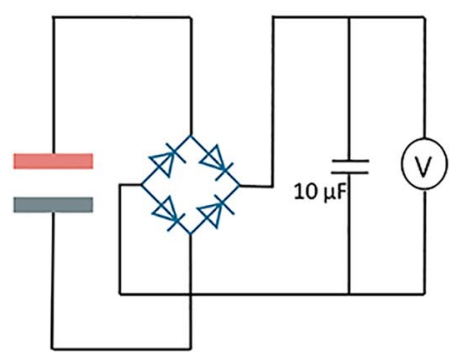

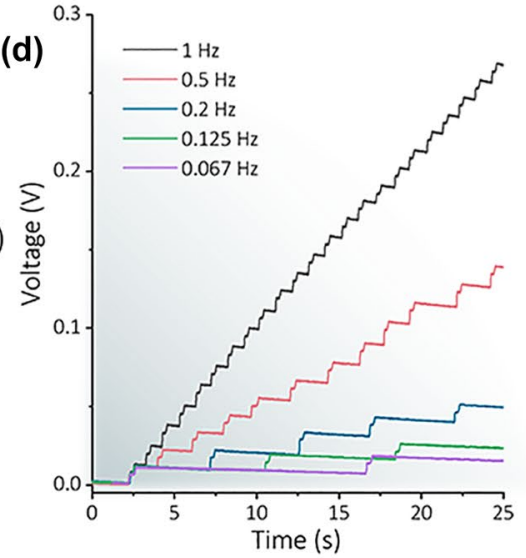

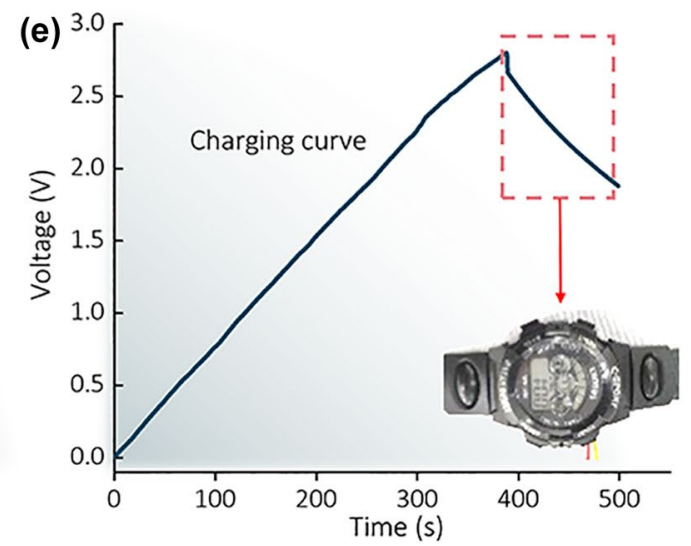

(f)

(g)

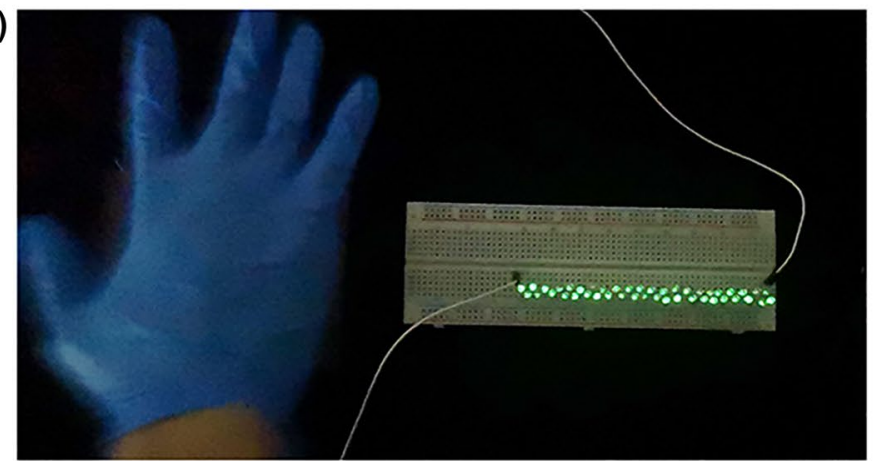

Fig. 8 Applications of EHTs: a Schematic illustration of the use of EHTs as wearable power generation fabrics and floors to harvest energy from human motion. b (i) Schematic diagram of connection between the energy harvesting floor and LEDs shaped into the letters "STU" and "BMG." (ii) Photograph of the energy harvesting floor driving the LEDs shaped into the letters "STU." (iii) Schematic diagram of the reversed connection between the energy harvesting floor and LEDs that make up the letters "STU" and "BMG." (iv) Photograph of the LEDs shaped into the letters "BMG" lighted up by the reversely connected energy harvesting floor. c Circuit diagram of the energy harvesting floor to continuously charge a capacitor of $10 \mu \mathrm{F}$ with a rectifier. d Measured voltage of a $10-\mu \mathrm{F}$ capacitor charged by the energy harvesting floor at different frequencies. e Charging curve of a $100-\mu \mathrm{F}$ capacitor charged by the energy harvesting floor at a frequency of $5 \mathrm{~Hz}$. The inset shows the photograph of charged capacitor to power an electronic watch. f Photograph of multilayered EHTs with four-unit numbers connected in parallel. $\mathbf{g}$ Photograph of 46 green LEDs connected in parallel powered by the resulting multilayered SF/PTFEF EHTs (ambient humidity: b at 50\%, d, e at $37 \%$, and $\mathbf{g}$ at $65 \%$ ) (Color figure online) 